\title{
ПСИХОЛОГИЯ РАЗВИТИЯ
}

УДК 159.9

\author{
О. В.Гусева, И. И. Мамайчук
}

\section{ОСОБЕННОСТИ ПСИХИЧЕСКОЙ АДАПТАЦИИ ЗДОРОВЫХ СИБЛИНГОВ В СЕМЬЯХ, ИМЕЮЩИХ ДЕТЕЙ С РАССТРОЙСТВАМИ АУТИСТИЧЕСКОГО СПЕКТРА}

\begin{abstract}
Рассматриваются особенности психической адаптации сиблингов, имеющих брата или сестру с расстройствами аутистического спектра (РАС). Выявлены аффективная неустойчивость, фрустрационная напряженность, тревожность здоровых сиблингов. Показано, что отношения сиблингов изучаемой группы к сиблингами с РАС отличаются амбивалентностью, что обусловлено необходимостью повышенного надзора за «особенными» братьями или сестрами, ревностным отношением к родителям, а также пессимистическими оценками будущего сибсов с РАС. Установлено, что сиблинги исследуемой группы менее приспособлены к соблюдению общепринятых социальных стандартов. Библиогр. 31 назв. Табл. 3.

Ключевые слова: сиблинги, расстройства аутистического спектра, психическая адаптация, семейные отношения.
\end{abstract}

\section{O. V. Guseva, I.I. Mamaychuk}

\section{MENTAL ADAPTATION PECULIARITIES OF HEALTHY SIBLINGS IN FAMILIES WITH CHILDREN WITH AUTISTIC SPECTRUM DISORDERS}

The paper is focused on the peculiarities of psychic adaptation of siblings with a brother or sister with autism spectrum disorders (ASD). The study was carried out with an experimental group consisting of 31 healthy siblings, each with a sibling with ASD. The age of healthy children and adolescents was from 6 to 17 years with an average age of 12 years. The age of siblings with ASD was 5 to 17 years, the average age was 9 years. The average age of parents is 40 years. In terms of the severity of the disease of children with ASD, two groups were identified: $81 \%$ (25) siblings with severe autism, and 19\% (6) with moderate severity. The control group included 30 families with healthy siblings.

It was found that among siblings having brother or sister with ASD, emotional instability was observed in the personality structure, which was manifested in high frustration, anxiety, affective

Гусева Ольга Владимировна - соискатель, Санкт-Петербургский государственный университет, Российская Федерация, 199034, Санкт-Петербург, Университетская наб., 7-9; guseva_ov@skcfmba.ru, olgaguseva4@mail.ru

Мамайчук Ирина Ивановна - доктор психологических наук, Санкт-Петербургский государственный университет, Российская Федерация, 199034, Санкт-Петербург, Университетская наб., 7-9; medical.psychology@spbu.ru, mauki@mail.ru

Guseva Olga V. - postgraduate student, Saint Petersburg State University, 7-9, Universitetskaya nab., St. Petersburg, 199034, Russian Federation; guseva_ov@skc-fmba.ru, olgaguseva4@mail.ru

Mamaychuk Irina I. - Doctor of Psychology, Saint Petersburg State University, 7-9, Universitetskaya nab., St. Petersburg, 199034, Russian Federation; medical.psychology@spbu.ru, mauki@mail.ru

( С Санкт-Петербургский государственный университет, 2017 
rigidity, a tendency to self-incriminating behavior in a conflict situation, with a reliably high control over emotions, in comparison with children and adolescents of the control group. The level of psychological and socio-psychological adaptation in the experimental group was significantly lower than in the control group. It was shown that the relationship between siblings of the experimental group express ambivalence, which was due to the need for increased supervision of siblings with ASD, zealous relations to parents, as well as pessimistic assessments of the future of their siblings with ASD. It has been established that the siblings of the experimental group were less able to comply with generally accepted social standards. Refs 31 . Tables 3 .

Keywords: siblings, autism spectrum disorder, mental adaptation, family relationship.

В настоящее время значительное количество работ посвящено исследованиям семей, воспитывающих детей с расстройствами аутистического спектра (РАС) [1-7]. Однако подавляющее большинство исследований посвящено родительскодетским отношениям в системе «мать - больной ребенок». Незначительное количество работ рассматривает отцовские отношения к ребенку с РАС [8-10]. Практически отсутствуют исследования, рассматривающие семью в целом, включая сравнительный анализ родительских отношений к больному и здоровому ребенку внутри семьи, а также здоровых детей к сибсам с РАС.

Основными проявлениями РАС у детей являются качественные нарушения коммуникации и социального взаимодействия не только в социуме, но и с членами семьи. Нарушение возможности активно взаимодействовать со средой, проявляемое в снижении жизненного тонуса, в ощущении дискомфорта в контактах с окружающими, указывает на повреждение базовых механизмов аффективной регуляции. Эти нарушения обусловливают искажение и задержку развития системы эмоциональной организации в целом и в дальнейшем осложняют адаптацию детей к социальным условиям [11-13]. Как отмечают некоторые авторы, качественные изменения семейного функционирования в семьях детей с РАС проявляются на психологическом, социальном и соматическом уровнях [14]. Стресс, наблюдаемый у родителей в связи с трудностями воспитания детей с РАС и недостатком всесторонней профессиональной помощи, оказывает сильное деформирующее воздействие на семейное функционирование не только у родителей, но и у других членов семьи: здоровых сиблингов, прародителей и других родственников [15-17]. Как отмечает M. Seligman, в зоне «психологического риска» нередко оказываются сиблинги детей с РАС [18]. Исследования других иностранных авторов показывают, что братья и сестры детей с нарушениями имеют больше домашних обязанностей, чем братья и сестры здоровых детей, однако эти обязанности далеко не всегда приводят к негативным последствиям [19-22]. В исследованиях B. Siegel и S.Silverstein подчеркивается, что важную роль в развитии приспособленности к семейной ситуации в семьях детей с РАС играют личностные особенности сиблингов. И чем менее угнетена и эмоционально подавлена мать, тем лучше живется детям [23]. В исследованиях отечественных авторов подчеркивается, что наличие в семье с детьми с РАС здоровых сибсов (независимо от порядка рождения) оказывает благотворное влияние на семейный микроклимат [24].

Целью нашего исследования являлось изучение особенностей психической адаптации и системы отношений здоровых сиблингов в семьях, воспитывающих детей с РAC. 


\section{Методы}

В исследовании принимал участие 31 здоровый сиблинг, имеющий брата (сестру) с РАС. Возраст здоровых детей и подростков составлял от 6 до 17 лет, средний возраст 11,6 лет. Возраст сибса с РАС - от 5 до 17 лет, средний возраст 8,7 лет. Средний возраст родителей -40 лет. Группы сравнения были сбалансированы по полу и возрасту обследуемого сиблинга, полу родителей, возрасту родителей, а также по составу семьи. По степени тяжести заболевания детей с РАС клиницистами были выделены две подгруппы: 81 \% (25) детей с тяжелой степенью аутизма и $19 \%$ (6) со средней степенью тяжести. В контрольную группу входило 30 семей, воспитывающих здоровых детей, и, соответственно, 30 сиблингов. Возраст здоровых детей и подростков составлял от 7 до 17 лет, средний возраст 12,4 года. Возраст второго сиблинга составлял от 5 до 17 лет, средний возраст 9,2 года.

Были использованы как экстенсивные методы (метод направленного наблюдения, беседы с членами семьи), так и интенсивные методы (методика Кеттелла для исследования структуры личности сиблингов [25], тест Розенцвейга для оценки особенностей фрустрационной толерантности здоровых сиблингов [26; 27], цветоассоциативный тест отношений (ЦТО) [28]). Учитывая разный возраст обследуемых, мы использовали два варианта методики Кеттелла - детский (12PF) для детей 8-12 лет и юношеский (14PF) для подростков, а также два варианта теста Розенцвейга - детский и взрослый. Для исследования системы отношений здоровых сиблингов был разработан модифицированный вариант методики «Незаконченные предложения», включающий в себя следующие блоки:

1. Отношение к семье в целом.

2. Отношения с братом или сестрой.

3. Отношение окружающих к брату или сестре в представлении сиблинга.

4. Позиция (активная, пассивная или безразличная) сиблингов к брату или сестре.

5. Отношение родителей к брату или сестре в представлении сиблинга.

6. Будущее брата или сестры в представлении сиблинга.

Дети и подростки из семей контрольной группы обследовались по той же схеме, что и экспериментальная группа (сиблинги с РАС).

\section{Результаты исследования}

С целью сравнительного анализа личностных особенностей детей и подростков, имеющих сиблингов с РАС, и детей и подростков, имеющих здоровых сиблингов, были проанализированы показатели совокупности факторов, полученных при использовании методики Кеттелла, и их взаимосвязи по трем основным блокам [29]:

- эмоциональная устойчивость (факторы C, G, I, O, Q3, Q4);

- эмоциональные переживания (факторы Н, О, Q4);

- контроль над эмоциями (факторы C, Q3).

Полученные данные по средним показателям эмоционально-волевой неустойчивости, эмоциональных переживаний и контроля над эмоциями представлены в таблице 1. 
Таблица 1. Средние показатели эмоционально-волевой неустойчивости, эмоциональных переживаний и контроля над эмоциями

\begin{tabular}{|l|c|c|c|c|}
\hline \multicolumn{1}{|c|}{ Название блока } & $\begin{array}{c}\text { Факторы, } \\
\text { входящие в блок }\end{array}$ & Достоверность & $\begin{array}{c}\text { Сиблинги } \\
\text { экспериентальной } \\
\text { группы }\end{array}$ & $\begin{array}{c}\text { Сиблинги } \\
\text { контрольной } \\
\text { группы }\end{array}$ \\
\hline $\begin{array}{l}\text { Эмоционально-волевая } \\
\text { неустойчивость }\end{array}$ & $\begin{array}{c}\mathrm{C}-, \mathrm{G}-, \mathrm{I}-, \mathrm{O}+, \\
\mathrm{Q}_{3}-, \mathrm{Q}_{4}+\end{array}$ & $p \leq 0,05$ & 7,92 & 4,9 \\
\hline $\begin{array}{l}\text { Эмоциональные } \\
\text { переживания }\end{array}$ & $\mathrm{H}-, \mathrm{O}^{+}, \mathrm{Q}_{4}+$ & $p \leq 0,05$ & 8,17 & 4,5 \\
\hline Контроль над эмоциями & $\mathrm{C}-, \mathrm{Q}_{3-}-$ & $p \leq 0,05$ & 7,44 & 5,9 \\
\hline
\end{tabular}

Анализ данных по методике Кеттелла показал, что у сиблингов, имеющих брата или сестру с РАС, наблюдаются достоверно высокие показатели по факторам эмоциональной неустойчивости, эмоциональных переживаний при наличии достоверно высокого контроля над эмоциями по сравнению с детьми и подростками контрольной группы. Это проявляется в ощущении неопределенной, беспредметной опасности, внутреннем беспокойстве, раздражительности, в эмоциональной неустойчивости.

Анализ особенностей реагирования на фрустрацию по методике Розенцвейга показал, что у сиблингов, имеющих сибса с РАС, наблюдается достоверно высокое количество реакций OD, отражающих повышенную фиксацию на источники конфликта, а также достоверно низкое число необходимо-упорствующих реакций (NP). Также было выявлено преобладание самозащитных реакций, отражающих сниженную потребность в разрешении конфликта. Показатель коэффициента групповой конформности в группе сиблингов, имеющих сибса с PAC (GCR эксперимент $=45,7 \pm 2,02)$, достоверно ниже, чем в контрольной группе (GCR контроль $=$ $63,5 \pm 2,2)$. Эти данные подчеркивают большую приспособленность детей контрольной группы к общепринятым социальным стандартам, в отличие от детей и подростков, имеющих сиблингов с РАС.

Были проанализированы особенности уровня психической дезадаптации исследованной группы. Для количественного анализа уровня психической дезадаптации была предложена следующая формула, которая апробирована в ряде исследований [30, с. 96-97].

$$
\text { ПД }=\left(\mathrm{OD}+\mathrm{M}+\mathrm{Q}_{4}\right) / \mathrm{C},
$$

где ПД - показатель психической адаптации;

$\mathrm{OD}$ - показатель реакций с фиксацией на препятствии;

M - показатель импунитивного реагирования на конфликт;

$\mathrm{Q}_{4}$ - показатель фрустрационной напряженности;

C - показатель интеграции поведения.

В результате проведенных вычислений было определено, что значение показателя ПД $(5,5 \pm 1,01)$ в группе сиблингов, имеющих сибса с РАС, находится в диапазоне неустойчивой психической адаптации (от 3 до 7 баллов), что проявляется в аффективной неустойчивости, повышенной тревожности, фрустрированности.

Были рассмотрены особенности психической адаптации сиблингов сибсов с РАС на социально-психологическом уровне и проведен анализ данных по моди- 
фицированной методике «Незаконченные предложения». Полученные усредненные показатели отношений к семье и близкому окружению в экспериментальной и контрольной группах представлены в таблице 2.

Таблица 2. Средние показатели отношений к семье и близкому окружению для экспериментальной и контрольной групп

\begin{tabular}{|l|c|c|c|}
\hline \multicolumn{1}{|c|}{ Параметры системы отношений } & $\begin{array}{c}\text { Экспериментальная } \\
\text { группа }\end{array}$ & $\begin{array}{c}\text { Контрольная } \\
\text { группа }\end{array}$ & $\begin{array}{c}\text { Достоверность } \\
\text { различий }\end{array}$ \\
\hline Блок 1. Отношение к семье в целом & 2,97 & 1,57 & $p=0,007$ \\
\hline Блок 2. Отношения с братом или сестрой & 0,32 & 0,53 & $p=0,760$ \\
\hline $\begin{array}{l}\text { Блок 3. Отношение окружающих к брату или } \\
\text { сестре в представлении сиблинга }\end{array}$ & -1 & 1,63 & $p=0,000$ \\
\hline $\begin{array}{l}\text { Блок 4. Позиция (активная, пассивная или } \\
\text { безразличная) сиблингов к брату или сестре }\end{array}$ & $-0,77$ & 1,70 & $p=0,000$ \\
\hline $\begin{array}{l}\text { Блок 5. Отношение родителей к брату или се- } \\
\text { стре в представлении сиблинга }\end{array}$ & $-0,03$ & 0,50 & $p=0,273$ \\
\hline $\begin{array}{l}\text { Блок 6. Будущее брата или сестры в представ- } \\
\text { лении сиблинга }\end{array}$ & 0,06 & 2,43 & $p=0000$ \\
\hline
\end{tabular}

В результате количественного анализа данных было выявлено, что сиблинги из экспериментальной группы имеют различия на высоком уровне статистической значимости $(p \leq 0,01)$ по блокам «отношение к семье в целом», «отношение окружающих к брату или сестре в представлении сиблинга», «позиция (активная, пассивная или безразличная) сиблингов к брату или сестре», «будущее брата или сестры в представлении сиблинга».

Качественный анализ показал, что сиблинги из экспериментальной группы по сравнению с ровесниками из контрольной группы более лояльно относятся к своей семье, страдают от проявления отрицательного внимания со стороны окружающих, вынужденно занимают активную позицию по отношению к сибсу с РАС и имеют пессимистический взгляд на его будущее. Содержательный анализ ответов первого блока (отношение к семье в целом) показал, что в экспериментальной группе ответы в основном носят позитивный характер.

Ответы «Моя семья... любимая... дружная... хорошая... самая счастливая» говорят о том, что сиблинги, имеющие сибса с РАС, склонны воспринимать свою семью в более благоприятном свете, чем сиблинги контрольной группы.

При анализе третьего блока (отношение окружающих к брату или сестре в представлении сиблинга) был отмечен высокий уровень негативного отношения окружающих к сиблингу с РАС (45\% случаев, 14 человек). На утверждение «окружающие относятся к моему брату (сестре)...» были получены следующие ответы: как к уурачку; с презрением; с ужасом; с непониманием; косо смотрят; странно, когда она (сестра) кричит. Также в экспериментальной группе в $35 \%$ случаев (11 человек) по сравнению с $3 \%$ случаев (1 человек) в контрольной группе сиблингов отмечалось негативное отношение их друзей к своему брату (сестре). Причем 4 человека (13\%) из экспериментальной группы закончили предложение «Мои друзья относятся к моему брату (сестре)...» следующим образом: Они не знают о нем; честно, я не знаю, он им не подходит. 
Содержательный анализ ответов четвертого блока (позиции сиблингов к брату или сестре «активная», «пассивная» или «безразличная») показывает, что здоровые братья и сестры экспериментальной группы выполняют в семье своеобразную роль «няньки» при сиблинге с РАС. Большинство смирилось с этим, а некоторые протестуют против такого положения дел. Ниже приведены два примера типичных ответов. На утверждение «когда мы приходим с моим братом (сестрой) в гости и там много детей, я...» Костя П., 15 лет, ответил: всегда смотрю за ним, а Таня Т., 8 лет, сказала: обычно играю с этими детьми, а Мима (брат) сидит и что-то ecm. При этом все опрашиваемые подтвердили, что не дадут в обиду своего сиблинга с PAC.

Качественный анализ данных пятого блока (отношение родителей к брату или сестре в представлении сиблинга) показывает, что в большинстве семей с ребенком с РАС у сиблингов присутствует ревность, переживания о том, что родители уделяют больше внимания сибсу с РАС.

Анализируя предложения шестого блока (будущее брата или сестры в представлении сиблинга), можно заключить, что сиблинги из экспериментальной группы не видят позитивного будущего их братьев и сестер с РАС. Часто они опасаются, что во взрослой жизни им также придется ухаживать за своими братьями и сестрами с РАС. Например, Семен С., 15 лет, утверждает: Когда мой брат вырастет, мне придется смотреть за ним. Также большинство детей и подростков ответили, что им очень хочется, чтобы их сиблинг с РАС выздоровел; нашел место в жизни; научился говорить; пошел в школу...

Таким образом, в ответах сиблингов экспериментальной группы, в отличие от их сверстников из контрольной группы, прослеживается желание представить свою семью в идеальном ракурсе, они страдают от стигматизации своей семьи в обществе и нередко скрывают своего брата (сестру) с РАС. Их отношения с братьями и сестрами с РАС носят амбивалентный характер, часто они играют роль «няньки» при особом сибсе и опасаются, что и во взрослой жизни им придется заботиться о них. Также сиблинги из экспериментальной группы пессимистически оценивают будущее своих братьев и сестер с РАС.

С целью оценки эмоциональных отношений сиблингов к сибсам в обеих группах был использован цветовой тест отношений [28; 31]. В таблице 3 представлены цветовые предпочтения сиблингов.

Анализ показывает, что сиблинги из семей, имеющих детей с РАС, достоверно чаще идентифицируют себя с серым цветом, что отражает неудовлетворенность, безразличие, возможную внутреннюю отгороженность и дезадаптацию личности. Сиблинги экспериментальной группы больше всего ассоциируют себя с фиолетовым $(22,6 \%)$ и желтым цветами $(22,6 \%)$. Фиолетовый цвет характеризует эмоциональную незрелость, снижение адаптационных возможностей, а желтый цвет говорит о ведущей потребности в эмоционально насыщенном взаимодействии. На третью позицию по частоте встречаемости выходит зеленый цвет $(16,1 \%)$, который свидетельствует о потребности в отстаивании собственной позиции, стремлении к самоутверждению. Отметим, что сиблинги контрольной группы с одинаковой частотой $(20 \%)$ для самообозначения выбирают фиолетовый, желтый и красный цвета. Красный цвет отражает стенический тип реагирования и выявляет потребность в активности, лидерские черты. 
Таблица 3. Цветовые предпочтения сиблингов

в экспериментальной и контрольной группах к членам семьи

(в процентах по отношению к общему числу испытуемых в группе)

\begin{tabular}{|l|c|c|c|c|c|c|c|c|}
\hline & \multicolumn{3}{|c|}{ Экспериментальная группа } & \multicolumn{3}{c|}{ Контрольная группа } \\
\hline $\begin{array}{c}\text { Название цвета } \\
\text { (соотв. тесту } \\
\text { Люшера) }\end{array}$ & Я & Сиблинг & Мама & Папа & Я & Сиблинг & Мама & Папа \\
\hline & $\%$ & $\%$ & $\%$ & $\%$ & $\%$ & $\%$ & $\%$ & $\%$ \\
\hline Серый & 9,7 & 6,5 & 6,5 & 3,3 & 3,4 & 3,3 & 3,4 & 3,4 \\
\hline Синий & 12,9 & 6,5 & 3,2 & 30 & 13,3 & 3,3 & 3,4 & 30,1 \\
\hline Зеленый & 16,1 & 19,3 & 19,3 & 6,7 & 13,3 & 23,4 & 0 & 39,7 \\
\hline Красный & 12,9 & 16,1 & 19,3 & 20 & 20 & 33,4 & 39,7 & 10 \\
\hline Желтый & 22,6 & 25,8 & 22,6 & 10 & 20 & 16,6 & 20,1 & 10 \\
\hline Фиолетовый & 22,6 & 12,9 & 22,6 & 6,7 & 20 & 10 & 30 & 0 \\
\hline Коричневый & 0 & 9,7 & 6,5 & 10 & 6,6 & 10 & 3,4 & 3,4 \\
\hline Черный & 3,2 & 3,2 & 0 & 13,3 & 3,4 & 0 & 0 & 3,4 \\
\hline
\end{tabular}

Брат или сестра с РАС преимущественно ассоциируются у здоровых сиблингов с желтым цветом (25,8\%). Желтый цвет соотносится с такими личностными характеристиками, как разговорчивый, безответственный, энергичный, напряженный. Второе место занимает зеленый цвет (19,3\%), который воспринимается как доминантный, интровертированный, что соответствует тому, какое особое место в семье занимает ребенок с РАС. На третьей позиции по частоте встречаемости находится красный цвет $(16,1 \%)$, для которого характерны значения активности, экстраверсии.

Сиблинги из контрольной группы отождествляют своего сибса в трети случаев $(33,4 \%)$ с красным цветом, что подчеркивает восприятие брата или сестры как доминантного и конкурентного. На второй позиции также находится зеленый цвет $(23,4 \%)$, а на третьей - желтый $(16,6 \%)$.

Средние значения показателей валентности по параметру «Сиблинг» не достигают статистически значимых различий, однако имеется тенденция к статистически значимым различиям показателя нормативности $(p=0,08)$ (экспериментальная группа $-3,55$; контрольная группа $-2,70)$.

На основании данных использования методики ЦТО были проанализированы особенности эмоциональных контактов сиблингов к сибсам в экспериментальной и контрольной группах

Данные результаты свидетельствуют о том, что большая часть сиблингов из обеих групп склонна эмоционально принимать своего сибса (ЭГ - 54,5\%, КГ $59,6 \%$ ), эмоциональное отвержение свойственно $19,5 \%$ испытуемых ЭГ и $6,8 \%$ испытуемых КГ, амбивалентное отношение свойственно $26 \%$ сиблингов ЭГ и 33,6\% сиблингов КГ. Обнаружены различия по эмоциональному отвержению (почти в три раза), что свидетельствует о более высоком эмоциональном отвержении своего «особого» брата или сестры сиблингами исследуемой группы. 


\section{Выводы}

У сиблингов, имеющих сибсов с РАС, в структуре личности наблюдаются эмоциональная неустойчивость, что проявляется в высокой фрустрированности, тревожности, аффективной ригидности, склонности к самообвинительному поведению в ситуации конфликта при наличии достоверно высокого контроля над эмоциями по сравнению с детьми и подростками контрольной группы. Уровень психической и социально-психологической адаптации у них достоверно ниже, чем у сверстников, имеющих в семье здоровых сибсов.

Отношение к семье в целом у сиблингов, имеющих сибса с РАС, в основном носит противоречивый характер. В отличие от их сверстников контрольной группы прослеживается желание представить свою семью в идеальном ракурсе, выявлены переживания за свою семью и тенденция скрыть наличие брата или сестры с РАС от окружающих.

Отношения здоровых сиблингов к сибсам с РАС отличаются амбивалентностью, что обусловлено необходимостью повышенного надзора за больными братьями или сестрами, ревностным отношением к родителям, которые уделяют много внимания больному ребенку, а также пессимистическими оценками будущего сибсов с РАС. Так же как и сиблинги из контрольной группы, они эмоционально привязаны к сибсам, переживают за их неудачи и радуются успехам.

Полученные данные важны в психокоррекционной работе с семьей, имеющей ребенка с РАС. Включение сиблингов, имеющих сибса с РАС, в психокоррекционный процесс является важным фактором в гармонизации отношений внутри семьи, в повышении эффективности семейного воспитания не только ребенка с РАС, но и здоровых сиблингов.

\section{Литература}

1. Печникова Л.С. Особенности материнского отношения к детям с ранним детским аутизмом: автореф. дис. ... канд. психол. наук. М., 1997. 144 с.

2. Печникова Л. С. Материнское отношение к ребенку-аутисту в зависимости от наличия в семье здорового сибса // Материалы Всероссийской научно-практической конференции «Социальное и душевное здоровье ребенка и семьи: защита, помощь, возвращение в жизнь»: Тез. докл. М.: МГУ, 1998. С. $173-174$.

3. Карвасарская И.Б. Психологическая помощь аутичной семье // Психосоциальные проблемы психотерапии, коррекционной педагогики, специальной психологии: Мат-лы III съезда РПА и науч.-практ. конф. Курск: Изд-во Курск. гос. ун-та, 2003. 271 с.

4. Высотина Т.Н. Особенности родительского отношения к детям с атипичным аутизмом: автореф. дис. ... канд. психол. наук. СПб., 2013. 22 с.

5. Мамайчук И. И. Помощь психолога детям с аутизмом. СПб.: Эко-Вектор, 2014. 335 с.

6. Мамайчук И.И., Шабанова Е.В. Учет защитных механизмов личности родителей, детей с расстройством аутистического спектра в процессе психологической помощи // Вестник ЛГУ им. А. С. Пушкина. Серия «Психология». 2014. Т. 5, № 1. С. 82-91.

7. Шабанова Е. В. Особенности системы детско-родительских и супружеских отношений в семьях, воспитывающих ребенка с расстройством аутистического спектра // Вестник СПбГУ. Сер. 12. 2013. Вып. 3. С. $80-86$.

8. Мамайчук И. И., Родина А. В. Особенности отцовских отношений и стилей семейного воспитания в семьях детей с аутистическими синдромами // XI Мнухинские чтения: Мат-лы междунар. науч. конф. СПб., 2013. С. 301-308.

9. Keller T., Ramisch J., Carolan M. Relationships of Children with Autism Spectrum Disorders and their Fathers // The Qualitative Report. 2014. Vol. 19, Article 66. P. 1-15. 
10. Braunstein V., Peniston N., Perelman A., Cassano M. C. The inclusion of fathers in investigations of autistic spectrum disorders // Research in Autism Spectrum Disorders. 2013. Vol. 7. P. 858-865.

11. Каган В.Е. Аутизм у детей. Л.: Медицина, 1981. 190 с.

12. Никольская О. С. Аффективная сфера человека. Взгляд сквозь призму детского аутизма. М.: Центр лечебной педагогики, 2000. 362 с.

13. Мамайчук И.И. Психокоррекционные технологии для детей с проблемами в развитии. СПб.: Речь, 2010. 400 c.

14. Левченко И.Ю., Ткачева В.В. Психологическая помощь семье, воспитывающей ребенка с отклонениями в развитии: метод. пособие. М.: Просвещение, 2008. 239 с.

15. Ткачёва В. В. О некоторых проблемах семей, воспитывающих детей с отклонениями в развитии // Дефектология. 1998. № 4. С. 4.

16. Галасюк И.Н. Проблема психической травматизации членов семьи инвалида // Вестник Московского государственного областного университета. Серия «Психологические науки». 2011. № 1. С. 54-60.

17. Селигман М., Дарлинг Р. Обычные семьи, особые дети. 3-е изд.. М.: Теревинф, 2013. 368 с. $712 \mathrm{p}$.

18. The family with a handicapped child / ed. M. Seligman. 2nd ed. Boston: Allyn \& Bacon, 1991.

19. Farber B. Family organization and crisis: Maintenance of integration in families with a severely mentally retarded child // Monographs of the Society for Research in Child Development. 1960. Vol. 25 (Whole No. 75). P. 1-95.

20. Grossman F. K. Brothers and sisters of retarded children. Syracuse; New York: Syracuse University Press, 1972. 249 p.

21. Bank S.P., Kahn M.D. The sibling bond. New York: Basic Books, 1982. 300 p.

22. Rolland J.S. Families, illness, and disability: An integrative treatment model. New York: Basic Books, 1994. 336 p.

23. Siegel B., Silverstein $S$. What about me? Growing up with a developmentally disabled sibling. New York: Plenum, 1994. 296 p.

24. Полоухина Е.А. Влияние наличия ребенка-инвалида в семье на характер брачно-семейных отношений: дис. ... канд. психол. наук / Санкт-Петербургская государственная педиатрическая медицинская академия. СПб., 2009. 144 с.

25. Александровская Э. М., Гильящева И. Н. Адаптированный модифицированный вариант детского личностного опросника Р. Кеттелла: Метод. рекомендации. М.: Фолиум, 1993. 40 с. (Научнометодическая серия «Психодиагностика детей и подростков»).

26. Тарабрина Н. П. Экспериментально-психологическая методика изучения фрустрационных реакций. Л.: НИПИ им. В. М. Бехтерева, 1984. 24 с.

27. Данилова Е. Е. Детский тест «Рисуночной фрустрации» С. Розенцвейга: Практ. руковод. М., 1992. $58 \mathrm{c}$.

28. Эткинд А. И. Цветовой тест отношений // Общая психодиагностика. М.: МГУ, 1987. С. 221227.

29. Мамайчук И. И., Смирнова М. И. Психологическая помощь детям и подросткам с расстройствами поведения. СПб.: Речь, 2010. 384 с.

30. Мамайчук И. И. Психология дизонтогенеза и основы психокоррекции. СПб.: Изд-во СПбГУ, 2000. $168 \mathrm{c}$.

31. Цветовой тест отношений: Метод. рекомендации / сост. Е.Ф.Бажин, А. М.Эткинд. Л.: НИПИ им. В. М. Бехтерева, 1985. 20 с.

Для цитирования: Гусева О.В., Мамайчук И. И. Особенности психической адаптации здоровых сиблингов в семьях, имеющих детей с расстройствами аутистического спектра // Вестник СПбГУ. Психология и педагогика. 2017. Т. 7. Вып. 2. С.169-179. DOI: 10.21638/11701/spbu16.2017.205.

\section{References}

1. Pechnikova L.S. Osobennosti materinskogo otnosheniia $k$ detiam s rannim detskim autizmom. Avtoreferat dissertatsii kand. psikhol. nauk [Features of maternal attitude towards children with early childhood autism. Thesis of PhD]. Moscow, 1997. 144 p. (In Russian)

2. Pechnikova L.S. [Maternal attitude to an autistic child depending on the presence of a healthy sibling in the family]. Materialy vserossiiskoi nauchno-prakticheskoi konferentsii "Sotsial'noe i dushevnoe zdorov'e rebenka i sem'i: zashchita, pomoshch', vozvrashchenie $v$ zhizn'”. Tez. dokl. [Social and mental health 
of the child and the family: protection, assistance, return to life. Materials of the Russian scientific practical conference]. Moscow, 1998, pp. 73-74. (In Russian)

3. Karvasarskaya I. B. [Psychological help to an autistic family]. Psikhosotsial'nye problemy psikhoterapii, korrektsionnoi pedagogiki, spetsial'noi psikhologii: Mat-ly III s"ezda RPA i nauch.-prakt. konf. [Psychosocial problems of psychotherapy, correctional pedagogy, special psychology: Materials of the III Congress of the Russian Psychotherapeutic Association and scientific-practical. Conf.]. Kursk, Publishing House of Kursk State University, 2003. 271 p. (In Russian)

4. Vysotina T. N. Osobennosti roditel'skogo otnosheniia $k$ detiam s atipichnym autizmom. Avtoref. dis. kand. psikhol. nauk [Features of parental relation to children with atypical autism. Thesis of PhD]. St. Petersburg, 2013. 162 p. (In Russian)

5. Mamaychuk I.I. Pomoshch' psikhologa detiam s autizmom [Psychologist's help to children with autism]. St. Petersburg, Eko-Vektor Publ., 2014. 335 p. (In Russian)

6. Mamaychuk I.I., Shabanova Ye. V. Uchet zashchitnykh mekhanizmov lichnosti roditelei, detei s rasstroistvom autisticheskogo spektra $\mathrm{v}$ protsesse psikhologicheskoi pomoshchi [Accounting for the protective mechanisms of the personality of parents, children with autism spectrum disorder in the process of psychological assistance ]. Vestnik LGU im. A. S. Pushkina, 2014, vol. 5, no. 1, pp. 82-91. (In Russian)

7. Shabanova Ye. V. Osobennosti sistemy detsko-roditel'skikh i supruzheskikh otnoshenii v sem'iakh, vospityvaiushchikh rebenka s rasstroistvom autisticheskogo spektra [Features of the system of child-parental and marital relations in families raising a child with autism spectrum disorder]. Vestnik of SPbSU. Series 12, 2013, issue 3, pp. 80-86. (In Russian)

8. Mamaychuk I. I., Rodina A. V. [Peculiarities of paternal relations and styles of family education in families of children with autistic syndromes]. XI Mnukhinskie chteniia. Materialy mezhdunarodnoi nauchnoi konferentsii [XI Mnuhin Readings: Materials of the international scientific conference]. St. Petersburg, 2013, pp.301-308. (In Russian)

9. Keller T., Ramisch J., Carolan M. Relationships of Children with Autism Spectrum Disorders and their Fathers. The Qualitative Report, 2014, vol. 19, Article 66, pp. 1-15.

10. Braunstein V., Peniston N., Perelman A., Cassano M. C. The inclusion of fathers in investigations of autistic spectrum disorders. Research in Autism Spectrum Disorders, 2013, vol. 7, pp. 858-865.

11. Kagan V.Ye. Autizm u detei [Children's Autism]. Leningrad, Meditsina Publ., 1981. 190 p. (In Russian)

12. Nikol'skaya O. S. Affektivnaia sfera cheloveka. Vzgliad skvoz' prizmu detskogo autizma [The affective sphere of man. A look through the prism of children's autism]. Moscow, Tsentr lechebnoy pedagogiki Publ., 2000. 362 p. (In Russian).

13. Mamaychuk I. I. Psikhokorrektsionnye tekhnologii dlia detei s problemami v razvitii [Psychocorrection technologies for children with developmental problems]. St. Petersburg, Publ. Rech', 2010. 400 p. (In Russian)

14. Levchenko I. Yu., Tkacheva V.V. Psikhologicheskaia pomoshch' sem'e, vospityvaiushchei rebenka s otkloneniiami $v$ razvitii: Metodicheskoe posobie [Psychological help to a family raising a child with developmental disabilities: Methodical manual]. Moscow, Publ. Prosveshcheniye, 2008. 239 p. (In Russian)

15. Tkachova V.V. O nekotorykh problemakh semei, vospityvaiushchikh detei s otkloneniiami v razvitii [Some problems of families raising children with developmental disabilities]. Journal Defektologiia, 1998, no. 4, p. 4. (In Russian)

16. Galasyuk I. N. Problema psikhicheskoi travmatizatsii chlenov sem'i invalida [The problem of mental traumatization of family members of the disabled person]. Bulletin of the Moscow State Regional University. Series: Psychological sciences, 2011, no. 1, pp. 54-60. (In Russian)

17. Seligman M., Darling R. Obychnye sem'i, osobye deti [Ordinary families, special children]. $3^{\text {rd }}$ ed. Moscow, Publ. Terevinf, 2013. 368 p. (In Russian)

18. The family with a handicapped child. Ed. by M. Seligman. $2^{\text {nd }}$ ed. Boston, Allyn \& Bacon, 1991. $712 \mathrm{p}$.

19. Farber B. Family organization and crisis: Maintenance of integration in families with a severely mentally retarded child. Monographs of the Society for Research in Child Development, 1960, vol. 25 (Whole No. 75), pp.1-95.

20. Grossman F. K. Brothers and sisters of retarded children. Syracuse, NY, Syracuse University Press, 1972. $249 \mathrm{p}$.

21. Bank S. P., Kahn M.D. The sibling bond. New York, Basic Books, 1982. 300 p.

22. Rolland J.S. Families, illness, and disability: An integrative treatment model. New York, Basic Books, $1994.336 \mathrm{p}$. 
23. Siegel B., Silverstein S. What about me?: Growing up with a developmentally disabled sibling. New York, Plenum, 1994. 296 p.

24. Poloukhina Ye. A. Vliianie nalichiia rebenka-invalida $v$ sem'e na kharakter brachno-semeinykh otnoshenii. Dis. kand. psikhol. nauk [Influence of having a disabled child in the family on the nature of marriage and family relations. Diss. of PhD]. St. Petersburg, 2009. 144 p.

25. Aleksandrovskaya E.M., Gil'yasheva I.N. Adaptirovannyi modifitsirovannyi variant detskogo lichnostnogo oprosnika R. Kettella: Metod. rekomendatsii [Adapted modified version of the child personal questionnaire R.Cattell: Methodological recommendations]. Moscow, Publ. Folium, 1993. 40 p. (Nauchno-metodicheskaia seriia "Psikhodiagnostika detei i podrostkov" [Scientific and methodical series "Psychodiagnostics of children and adolescents"]). (In Russian)

26. Tarabrina N.P. Eksperimental'no-psikhologicheskaia metodika izucheniia frustratsionnykh reaktsii [Experimental-psychological method of studying frustration reactions]. Leningrad, NIPI im. V. M. Bekhtereva, 1984. 24 p. (In Russian)

27. Danilova Ye. Ye. Detskii test "Risunochnoi frustratsii" S. Rozentsveiga: Prakt. rukovod [Children's test of "Drawing frustration" S. Rosenzweig. A Practical Guide]. Moscow, 1992. 58 p. (In Russian)

28. Etkind A.I. [Color test of relations]. Obshchaia psikhodiagnostika [General psychodiagnostics]. Moscow, Moscow State University Press, 1987, pp. 221-227. (In Russian)

29. Mamaychuk I. I., Smirnova M. I. Psikhologicheskaia pomoshch' detiam i podrostkam s rasstroistvami povedeniia [Psychological assistance to children and adolescents with behavioral disorders]. St. Petersburg, Publ. Rech', 2010. 384 p. (In Russian)

30. Mamaychuk I. I. Psikhologiia dizontogeneza i osnovy psikhokorrektsii [Psychology dysontogenesis bases and psychological correction].St. Petersburg, St. Petersburg Univ. Press, 2000. 168 p. (In Russian)

31. Tsvetovoi test otnoshenii: Metod. rekomendatsii [Color test of relations. Guidelines]. Eds. Ye. F. Bazhin, A. M. Etkind. Leningrad, NIPI im. V. M. Bekhtereva, 1985. 20 p. (In Russian)

For citation: Guseva O. V., Mamaychuk I. I. Mental adaptation peculiarities of healthy siblings in families with children with autistic spectrum disorders. Vestnik SPbSU. Psychology and Education, 2017, vol. 7, issue 2, pp. 169-179. DOI: 10.21638/11701/spbu16.2017.205.

Статья поступила в редакцию 1 мая 2017 г. Статья рекомендована в печать 25 мая 2017 г. 